Human

\section{Experimentation: a Guided Step into the Unknown}

\author{
William A Silverman, Oxford, 204 \\ pages, $£ 20.00$, Oxford University \\ Press, 1985.
}

Silverman, formerly professor of paediatrics at Columbia University, New York, argues eloquently for the wider use of randomised trials when introducing new treatment, not least because therapies have become increasingly powerful ('medical weapons in a popular war') and so the potential for harm has increased enormously. The author's poignant main example - competing risks of perinatal mortality, blindness from retrolental fibroplasia, cerebal palsy, associated with different modifications of oxygen therapy for premature infants - is devastatingly well chosen to illustrate the fireworks factory thesis: 'It is better to curse the darkness than to light the wrong candle'.

The text is generously gilded with pithy parables, apt aphorisms and quaint quotations, such as 'God is the answer! But what is the question?' to introduce the chapter on framing the question. 'Knowing' in medicine is traced from a heritage of authoritarianism through the growth of scepticism and the spirit of Galilean experimentation to the randomised clinical trial. The third chapter on representative patients distinguishes between random and haphazard selection and lists some biases described by Sackett in specifying and selecting the study sample. The Sackett list appears as a boxed textual digression on a single page, but elsewhere in the book similar blocks of boxed illustrative text have been split between pages to tax the reader! Controlled comparison is introduced by an attributed, joyously exasperated expostulation on the pitfalls of interpreting retrospective experience: 'Looking backward: is it worth the crick in the neck?' A good chapter on intervention follows, the problems of flexible dosage, timing of intervention, monitoring of on-going effects and multiple end points being superbly illustrated in the retrolental fibroplasia (RLF) trial example. Moreover, an appendix on the RLF story makes fascinating, challenging reading - how could the research effort have been better directed? Chapters follow on accurate observation (chapter
6), with cunning illustrations, for example of measurement scales - a begging man's summary of his plight:

\begin{tabular}{ll} 
wars & 2 \\
legs & 1 \\
wives & 2 \\
children & 4 \\
bankruptcies & 2 \\
\cline { 2 - 2 } & 11
\end{tabular}

on the event of interest (chapter 7) and avoiding entrapment (chapter 8), (for example, in multicentre trials; the need to ensure external relevance and vigilance to thwart misguided sabotage - as when night nurses turned up the oxygen of premature babies randomised to curtailed oxygen therapy).

Silverman discourses divertingly, a generalist who has dabbled in philosophy, decision analysis (chapter 11), and experimental design but who readily invokes the authority of others by generous quotation from their writings when those contributions are well put. Silverman's own love of language and clever use of it attest to the sincerity of these references.

It is in respect of statistics that language occasionally becomes licence or illustrations are alarmingly simplistic, as in the illustration of a three-patient three-period cross-over design unbalanced for carryover. When the number of periods is odd, the smallest design which gives balance for first order carryover requires twice as many patients as periods. In discussing a chance difference in mortality the author notes that: 'Variations of this magnitude can be expected as the result of chance allocation of patients at relatively high risk to one treatment group'. Silverman's scenario is a sufficient, but not a necessary explanation. The vagary of statistical terminology, more than the author, is responsible for any misunderstanding that may derive from the statement: ' $a$ 95 per cent confidence interval, for example, is the 2 standard deviation range surrounding the observed value'. Paradoxically, statisticians use the term standard error to denote the standard deviation of a statistic.

The chapter on stopping rules (chapter 9) suggests that the magnitude of an 'important' difference should reflect a view of public gain or loss, yet the power functions which are illustrated on page 117 relate only to large target differences such as an increase from 30 per cent to 60 per cent response and could seem to promote trials with low power to detect more modest target differences. Human Experimentation: a Guided Step into the
Unknown is not a book on statistics (but see chapter 10) and so it is churlish of me to overemphasise these remarks except insofar as the final chapter, on the ethics of human experimentation, notes correctly that there is no point in obtaining informed consent to a useless study. Human experimentation must first reach the bealach ${ }^{\star}$ between statistics and ethics before a direct trial assault can proceed.

Silverman advocates informal surveillance via the patient's personal and disinterested physician and notes that general ethical propositions do not decide concrete cases. Is complete candour warranted or should the patient decide the extent of disclosure? Attitude surveys are referenced. The public character of scientific method is its best advocate and Silverman supports the principle of rationality and notes that: 'Science teaches us to doubt and, in ignorance, to refrain'.

This non-technical, well written, exampled text should appeal to public and professional readership alike and develops the sound ethical case for reasoned human experimentation.

SHEILA M GORE, MA PhD MRC Biostatistics Unit, Cambridg

Mental Health and Human Conscience the True and the False Self

E K Ledermann, Aldershot, Hants/ Brookfield, Vermont USA, 228 pages, $£ 7.95$ paperback, £20 hardback US $\$ 14.50$ paperback US $\$ 36$ cloth, Gower Publishing Co Ltd, 1984.

Existentialism will be familiar to few psychiatrists and fewer doctors whose empirical training has eschewed the study of philosophy. To others it will be indelibly associated with radical $40 \mathrm{~s}$ and 50 s intellectualism, the ideas of $J \mathbf{P}$ Sartre and a rather asocial, individualistic ethic. In this country $\mathbf{R}$ D Laing is the only major psychiatrist to have systematically applied existentialism to the concepts and treatment of mental illness and it is fashionable to decry his ideas as invalid and antitherapeutic.

Ledermann attempts a new and valuable exploration of such concepts and thereon develops a non-dogmatic existential therapy. His book is timely:

* Gaelic for a high pass or watershed [Editor]. 
it stands against the current hijack of mental health services by a scientific reductionist 'nothing but'ism which dehumanises man and reduces agency to mechanism, presided over by a psychiatric elite complete with training and research facilities and establishment approval. The current intellectual, moral and financial bankruptcy of such an approach makes the time ripe for a humanistic psychiatry which, as Ledermann suggests, gives a central role to the conscience, that still, small voice that calls man to authenticity rather than drug-induced suppression or manipulation: that affirms his freedom to change himself.

The book falls into two parts, a larger part stating Ledermann's conceptual framework and defining the roles of conscience, authentic and inauthentic guilt described in classical, non-theistic existential terms. This part is densely written and like much existential literature, at times turgid and difficult to follow. His ethic prefers Buber's 'IThou' relationship to Sartre's 'Hell is other people'; an unacknowledged influence is John MacMurray (Persons in Relation) who explores the philosophical basis of interpersonal psychology and therapy more adequately than here. There follows a quick run-through of alternative models of mental illness and its treatment which are rejected as deterministic, oppressive and invalid; psychoanalysis, behaviour therapy, anti-psychiatry, organic psychiatry and Gestalt therapy all being disposed of.

Ledermann is much influenced by Romantic notions of the true self which must be helped to declare itself for healing to occur through the therapist's appeal to the conscience. Although not explicitly identified with a religious impulse, a Low Church Christian, such as a Quaker, would have little difficulty in agreeing with this mode of approaching 'the road to freedom'. Likewise, although he explicitly negates Jung's metapsychology of inner objects, as indeed those of Freud and later object relations theorists, Ledermann's subsequent (and disappointingly brief) description of individual therapy implies a heavy reliance on elucidating the meaning and purpose of the individual's defences and avoidances in seeking freedom and selfactualisation; and is illustrated by dreams, reveries, hypnoidal states and drawings, none of them in practice different from the material of the Jungian analyst. While he rejects a reductionist analysis of behaviour to the resultant of mental structures, his illustrations of therapy in action disclose a reliance on developmental theory and the effects of adverse early experience prior to conscious recall, particularly within families. His picture of the development of therapy emphasises how increased selfrealisation and independence follow upon the recapitulation and remaking of failed earlier experience.

A number of unexplored issues could have been developed. One aspect of therapy appears to consist of verbal analysis and imaging of conflicts through dreams, resolved by imaging other solutions. Psychodrama would seem to be a more powerful and effective extension of this approach which Ledermann does not mention. Neither does he explore the important issue of the therapist's interpretations and their validity - his examples leave the reader unclear as to who interprets what, and how to know whether or not the interpretation is correct. The work of the German philosopher Gadamer on hermeneutics would amplify his account of therapy, emphasising as it does human understanding as engagement in Sartre's sense rather than trained, methodical technique. This raises the further question of training for the existential therapist in 'guided intuition', or how to understand another human being other than through technical understanding; an issue Ledermann hints at but does not develop.

One last point - to the uninformed, the publisher and author are very coy as to where and in what setting Ledermann works. This is particularly important as the average National Health Service consultant will declare Ledermann's approach interesting but impossibly time-consuming in view of the claims on his or her attention of acute psychosis and psychopathic behaviour. These Ledermann excludes from existential therapy until in remission on similar grounds to those of the Enlightenment savants: they illustrate loss of reason and moral sense, an appeal to which is the existential therapist's main recourse. Although steering a middle course between orthodox therapies for the very ill and a radical call to freedom for the not so ill, the boundaries of and rationale for this division is inadequately explored, Ledermann being content to categorise as 'illness' what cannot be appealed to. This seems a fundamental avoidance of a central issue and threatens to undermine the applicability of his entire theoretical stance.
STEPHEN LITTLE,

Freelance Child Psychiatrist and Psychotherapist, Kent

\section{Medizinische Ethik}

F J Illhardt, Berlin/Heidelberg/New York/Tokyo, 220 pages, DM 52.00, Springer-Verlag, 1985.

This book intends giving health-care trainees an introductory presentation of the most current and important topics in medical ethics. The issues are grouped in four categories: beginning of life, lifecrises, end of life, and research. Each topic is briefly presented and discussed, with occasional reference to its medical, philosophical or sociological context. Due to the compact format of the book, some relevant ethical problems are made short work of - triage spans only one page, abortion merely two. References include a number of pertinent European and American publications, but most reputed journals and periodicals in the field are ignored. Each topic is enriched by a brief account of the Federal German legal situation, provided by $\mathrm{H} \mathrm{G}$ Koch. An addendum reproduces numerous legal texts, regulations, declarations and bills of rights.

The author's ethical stance is that patients are fundamentally autonomous but in need of help. The emphasis on helplessness, which has a strong tradition in German meta-medical writings, makes it all too easy to restrict or cancel autonomy. Illhardt in fact does so when defending resuscitation of suicidal individuals or when justifying the occasional interruption - or forced continuation - of therapy against patients' will, based on his view that patients ultimately decide 'under pressure'. To buttress his 'provisional' or situational kind of ethics, the author all too often resorts to contingent, ambiguous or even contradictory rhetoric. Thus, Illhardt condemns compulsory commitment of the mentally disabled but accepts that in certain instances - which he doesn't specify - it may be unavoidable. Abortion is rejected but reconsidered on second thoughts if extensive counselling fails. On the one hand, artificial insemination is eyed with suspicion because it disrupts the natural course of events. On the other hand, nature's course should actively be interfered with in decisions concerning resuscitation. Although he more than once employs them, the author explicitly dismisses arguments based on 